\title{
Benchmarking as an instrument of marketing decisions
}

\author{
N.Skryhun ${ }^{1}$, S. Kolodiuk ${ }^{2}$ \\ ${ }^{1,2}$ National University of Food Technologies, Kyiv, Ukraine
}

\begin{abstract}
Practical principles of benchmarking weight as marketing instrument of influence on strategic decisions of business development are studied in the article. Peculiarities of application and place of the tool are revealed and substantiated from ensuring competitiveness in the marketing portfolio. There is the procedure of benchmarking, and subsequent benchmarking of the received strategic data about the positive or negative experience of the competitor, which significantly affects its competitiveness is considered.
\end{abstract}

Keywords: competitiveness, benchmarking (marketing intelligence), benchmarking report, benchmarking analysis, strategic data, competitor's experience.

\section{Introduction}

Historically, the company's way is not a straight line. It's a direct line that constantly changes its position from a great affection to subsidence. However, the consumer market is developing rapidly, more and more companies enter the market, and with the characteristic aggression to fight for the attention of the target audience, trying to get rid of competitors. This phenomenon is caused by rapid scientific, technological, and social development, which every day absorbs more and more industries and areas of human activity. As a consequence of dynamic progress, the issue of conducting a competitive struggle has become even more global and will be more convenient every day. Even real giant companies, professionals, who have been on the market for decades, are embarrassed about the situation when a very young company at one moment can regain a significant market share and create new barriers to business. That is why managers and other specialists of many companies and corporations understand that to earn money and predict their successful and profitable future - they need to be able to vector research and analysis of competitors of their and related industries from all sides. There is the real value of using such a marketing tool as benchmarking is revealed, which allows adopting strategic data, positive experience of a competitor, applying it in their own strategic decisions.

The benchmarking is one of the powerful and effective marketing tools, as it bases on a long-term strategy. It takes into account a huge number of factors, that can affect the position of the business in one way or another, forming a base of relevant conclusions and create a scenario of interaction with partners in the industry and inter-industry markets. So much attention is given by experts from marketing to the tool and a separate section in marketing researches.

\section{The results}

This issue was researched by the famous scientist Philip Kotler, who reveals the concept of benchmarking. Its importance is described in "Fundamentals of Marketing" in the "marketing research and marketing information system". Also, the information base for writing this work was formed by publications and scientific articles by I. A. Arencov, E. Bagiev, Jim Blythe, Clark Greg, Savelieva C. V., Salomeeva A and others. The study shows the processes of benchmarking. They are not standing still and always improve. This method is very effective for domestic enterprises. The practice demonstrates the possibility of increasing competitiveness, increasing the market part, and solving several internal tasks.

In conditions of the constant change of the external environment of the enterprise, marketers try to find new methods and ways of optimization of market activity, adhering and creating new rules in benchmarking to achieve the desired result. However, the actual problem remains an attitude among many enterprises and the erroneous understanding of the concept as a phenomenon, its essence, and its effectiveness. That is why the purpose of the article is to study modern trends in benchmarking as a tool for making marketing decisions, complementing the understanding of the phenomenon and the disclosure of opportunities that business gets from the use of legal intelligence.

In modern economic conditions benchmarking is considered to be a creative activity of strategy creation and optimization in the long term. It bases on the experience of the best companies-competitors of industry. Philip Kotler describes this exploration as: "the process of comparing a company's products and processes with those of its 
competitors or leading firms in other industries, to find ways to improve the quality of work". Commonly, all strategic decisions have been used by predecessors or competitors, similar to bicycle theory. Someone has already faced with such a problem or question, therefore, to save time and resources, it is more efficient to use the experience, already gained by another enterprise, had a positive result.

Historically, there is no evidence of the origin or origin of benchmarking. This term has been widely used in the professional lexicon by surveyors for a very long time. It was the name of starting points for measurement, and at the beginning of the twentieth century has acquired the meaning of a marketing tool for assessing the quality of the product of an enterprise with a similar product of another by several clearly defined criteria. One of the first to benchmarking was Henry Ford in the automotive industry. He equipped production lines with conveyor lines based on the positive experience of the Chicago slaughterhouse. It was thanks to this strategic decision to optimize production that the company became a leader in the global automotive market. Formation of the concept is necessarily closer to the 50th years of the last century, as a scientific category, this phenomenon connected with industrial tours of Japanese, the best enterprises of the countries of Europe and the USA to benchmark, and the further integration of relevant decisions on own business investigated. An important feature of this process was not the research of the enterprise as an object of management, but the processes at management levels. According to historical data, the Japanese were able to catch up with their global competitors, market leaders, and overtake them in the field of production by borrowing the positive experience of reference enterprises.

As an economic category, the term benchmarking was introduced in 1972 by the Cambridge Institute for Strategic Planning and takes on the meaning of the method for assessing the performance of business processes. This method began popularity in the 80 s of the last century, triggered by the economic crisis. Many companies were forced to resort to this technology. For example, the company "Hegoh" has raised the competitiveness thanks to a method of marketing intelligence, having resorted to the analysis of expenses for manufacturing and quality of production, in comparison with the Japanese competitors. As a result, the method became popular among other companies in the future.

Today, benchmarking is among the most common and effective methods used by large companies around the world. Interpretation of the category has been slightly complemented over time, subject to temporary changes in the development of society, the consumer market and scientific, and technological progress. Benchmarking is a systematic activity that involves the search, evaluation, and analysis of strategic information on the experience of best examples of industries and areas of activity that influence the adoption and shaping of future business strategy. This method excludes the factor of business size, areas, and sectors of activity, geographical location, and other factors that form strategies by other research methods (segmentation). It reveals a characteristic feature of the method, the experience of the company, therefore, it is not always a competitor. It is a part of the marketing strategy. It takes a special place in theoretical marketing, management, and organizational activity. Marketing technology can form new processes inside the enterprise, providing an opportunity for the satisfaction of demand. It improves the effective use of enterprise resources and strengthening of competitiveness. On the one hand, the method helps an enterprise to better evaluate its own goals, its objectives, and activities. On the other hand, to compare its indicators with those of a reference enterprise in this field.

In developed countries, this marketing toolkit is supported at the level of the state and is one of the reasons for economic recovery. In the USA, the International Benchmarking Association has been established, which unites a large number of organizations and large enterprises of different industries and spheres of activity, exchanging experience at different levels, even some countries take part in congresses at the state level. "The Benchmarking Exchange" was founded by benchmarking association to trade successful models of business processes. The method is very popular in Japan still.. Метод й досі залишається шалено популярним у Японії, країнах This method is popular in Japan, Central America, Western Europe, and several Scandinavian countries. Giants of the market such as IBM, Wal-Mart, Shell, Microsoft, Jonson \& Jonson, Ford, and others are regular customers of Benchmarking Partners, where there is an exchange of experience at the level of large enterprises, industry leaders.

This marketing instrument is absolutely legal and fundamentally similar to marketing intelligence. According to research methodology, benchmarking uses only open sources of information (official resources, company reports, industry periodical literature, the Internet, specialized exhibitions and workshops, business meetings), without any espionage. It allows for quick solutions and relatively changes with relatively high time and resource consumption. Typically, the benchmarking method is engaged in marketing analysts, because the information is formed within a certain framework and form a database for the analyst, which is later passed to marketing strategists to adapt to the business.

It is important to follow the chronological of the benchmarking process because it is necessary to keep in mind the goals that the company follows. There are different types of benchmarking, which depend on the scale of the research required. 
General, benchmarking is the most difficult to conduct and implement type, it allows you to compare the internal processes, and enterprises, belonging to completely different areas of economic and organizational activities. However, it provides the most effective internal organizational solutions to optimize competitiveness. Functional benchmarking provides comparative research with organizations operating in a common sphere of activity, but it is not an intra-industry competitor. The main advantages of this method are the simplicity of identifying functional leaders, finding the potential for adaptation, and solving the problem of confidentiality. However, this type has some difficulties in adapting the results of research to a specific enterprise.

Competitive benchmarking focuses on comparing business processes with a competitor company in a joint field of activity or with partner companies in related industries. The most popular kind in the Ukrainian market, especially it is loved to use domestic manufacturers.

Internal benchmarking carries out inside the enterprise, where the processes of different organizational units are comparing. The main goal of this method is to identify weaknesses that may lead to crises and effective methods of organizing production activities. This type has some characteristics as the simplicity of conducting, searching and collecting information (all stored in one place) and the speed of analysis.

Benchmarking never done by once, and its a very necessary point for understanding. This method requires periodic steps as the market is constantly changing and transforming following the trends and development of modern society and STP. It is necessary to follow other basic rules of the method as well:

1. Concentration on quality (improving product quality and motivation of staff);

2. Legality (it is forbidden to discuss with competitors issues affecting pricing);

3. Confident (any information is classified, within the study);

4. Mutual exchange (information should be provided by partners in same amounts);

5. Information usage rule (information is used exclusively for research purposes);

6. Preparation (coordination of all stages, signing contracts, research of open information about a partner).

So, based on the principles of the benchmarking method, it can be concluded that this is not a one-sided process, so it is necessary to observe both moral and ethical and legislative norms in its application. Direct comparisons are very beneficial, especially for strategic purposes, but it is necessary to obtain permission for comparison. The report on the research results includes analysis of both strengths and weaknesses of a particular enterprise and a competitor or other subject of comparison. Well, databases make repeated procedures much easier. Business executives should always remember and care about their image and market behavior, as an honest and decent partner is more trusted and will be willing to provide the necessary information.

\section{Conclusions}

Most people associate benchmarking with industrial espionage, which is illegal, but this is not the case at all, on the contrary, this method is allowed and supported by the state. Today it has been transformed into a whole method of studying and adapting important strategic breakdowns to achieve goals. Moreover, the world experience shows the high efficiency of this method, a striking example is Japanese companies, thanks to benchmarking took it to place in the international arena, in the minds of competitors and the wallets of consumers.

So, benchmarking is a marketing tool, a research method that allows businesses to improve and improve their competitive position by obtaining new knowledge about the experience of their competitors, partners, and leaders in other industries. It can compare both positive and negative sides of organizations, finds optimal methods of business processes optimization, significantly saving time and resources.

Summing up the above, we can generalize that benchmarking is of strategic importance for companies as a tool to influence marketing decisions. This method has great potential for use by domestic companies, as it is a great success to adopt the experience of Velikhov and successful foreign organizations. The modern world is too dynamic, so it is necessary to be agile and adapt quickly to changes to retain its positions and clients.

\section{References}

[1] Isaev G. A. Benchmarking application for improvement of quality and efficiency of bank operation. 2009. URL: https://cutt.ly/or2ruUS

[2] Racek S. V. Main tendencies and peculiarities of using benchmarking technology UPL: https://cutt.ly/zr2rauo

[3] Yaremenko L. N. Benchmarking as an effective technology to create competitive advantages of enterprises of Ukraine Scientific Bulletin "Young Scientist". 2018. URL: https://cutt.ly/Kr2rdrn 